\title{
SISTEM INFORMASI AUDIT ENERGI LISTRIK BERBASIS LARAVEL STUDI KASUS : GEDUNG D UNIVERSITAS WAHID HASYIM
}

\author{
Aan Faisal ${ }^{1 *}$, Agung Riyantomo ${ }^{2}$ \\ ${ }^{1,2}$ Jurusan TEKNIK INFORMATIKA , Fakultas TEKNIK, Universitas Wahid Hasyim \\ Jl. Menoreh Tengah X/22, Sampangan, Semarang 50236. \\ Email: aan.faisalal@gmail.com
}

\begin{abstract}
Abstrak
Audit energi merupakan salah satu upaya penghematan listrik yang dapat dilakukan. Dari proses audit energi dapat diketahui pola pemakaian beban yang tergolong efisien atau boros. Dalam melakukan proses audit energi diperlukan inovasi agar proses pengolahan data dapat dilakukan secara cepat dan menghemat biaya dengan merancang suatu perangkat lunak audit energi. Sistem ini dibangun menggunakan metodologi prototype dengan framework PHP yaitu Laravel versi 5.5 dan didukung dengan database MySQL untuk mengolah basis datanya. Hasil dari keluaran sistem dapat menjadi acuan utama bagi auditor dalam menentukan langkahlangkah yang tepat dalam penggunaan energi listrik yang efisien dan efektif. Bagi top manajemen, sistem ini dapat menjadi bahan pertimbangan dalam menentukan kebijakan penghematan energi, dan memberikan informasi lebih terperinci tentang biaya konsumsi energi listrik.
\end{abstract}

Kata kunci: Audit energi, IKE(Intensitas Konsumsi Energi), Listrik, Sistem informasi

\section{PENDAHULUAN}

Energi listrik merupakan kebutuhan yang diperlukan setiap manusia, semakin berkembangnya teknologi dan bertambahnya jumlah penduduk suatu negara maka kebutuhan energi listrik juga bertambah. Tidak sedikit manusia yang melakukan pemborosan energi listrik, sehingga upaya penghematan energi seefisien mungkin terus diterapkan.

Oleh karena itu, pemerintah banyak merencanakan pembangunan pembangkit listrik agar dapat memenuhi kebutuhan listrik dan mensejahterakan masyarakat. Tetapi pembangunan pembangkit listrik saja tidaklah cukup, sebab pembangunan pembangkit listrik membutuhkan dana yang tidak sedikit dan cenderung tidak seimbang dengan pertumbuhan penduduk dan industri yang semakin lama semakin meningkat. Salah satu metode yang sering dipakai untuk mengefisienkan pemakaian energi listrik adalah metode Audit Energi.

Pembuatan perangkat lunak ini bertujuan untuk memudahkan pengolahan data audit energi sehingga dapat diketahui apakah suatu bangunan telah memenuhi standar efisien dalam pemakaian energi listrik atau belum. Penggunaan perangkat lunak ini diharapkan juga dapat memudahkan pengguna untuk lebih cepat mengetahui adanya potensi pemborosan energi listrik, serta upaya penghematan energi listrik sehingga dapat menghemat waktu dan biaya. Pada penelitian tersebut berbasis pada objek pengelolaan dan evaluasi energi listrik yang pengukuran auditnya menggunakan perhitungan manual dan data yang dihasilkan masih berupa data yang rumit, maka dari itu masih perlu dikembangkan lagi dengan membuat suatu sitem informasi yang mempermudah pengelolaan data audit. Berdasarkan hal tersebut, maka perlu dilakukan penelitian lebih lanjut. Oleh karena itu penulis tertarik untuk mengangkat tema audit energi listrik ini dengan judul "Sistem Informasi Audit Energi Listrik Berbasis Laravel Dengan Studi Kasus : Gedung D Universitas Wahid Hasyim".

\section{KAJIAN PUSTAKA \\ 2.1 Audit Energi}

Audit energi adalah proses evaluasi pemanfaat energi dan identifikasi peluang penghematan energi serta rekomendasi peningkatan efisiensi pada pengguna sumber energi dan pengguna energi dalam rangka konservasi energi. Proses audit dapat dilakukan oleh auditor internal maupun eksternal namun auditor auditor tersebut wajib memiliki sertifikat kompetensi sesuai dengan peraturan perundang - undangan (ESDM, 2015). 


\subsection{IKE}

Intensitas konsumsi energi (IKE) listrik adalah besar nilai pemakaian energi listrik untuk setiap satuan luas bangunan dalam waktu setahun. Nilai IKE ini diperoleh dari audit awal energi listrik pada suatu fasilitas instansi yang bersangkutan (SNI, 2011).

$\mathrm{IKE}=\frac{\text { pemakaian energi listrik }(\mathrm{kWh})}{\text { luas bangunan }\left(\mathrm{m}^{2}\right)}$

Nilai IKE dapat dihitung dengan memperhatikan data seperti diperoleh pada tahap audit awal. Penghitungan mencakup :

a) Rincian luas bangunan gedung dan luas total bangunan gedung $\left(\mathrm{m}^{2}\right)$.

b) Konsumsi Energi bangunan gedung per tahun ( $\mathrm{kWh} /$ tahun).

c) Intensitas Konsumsi Energi (IKE) bangunan gedung per tahun (kWh/m.tahun).

d) Biaya energi bangunan gedung $(\mathrm{Rp} / \mathrm{kWh})$.

\subsection{Laravel}

Laravel merupakan sebuah framework PHP open source yang dibuat oleh Taylor Otwell yang dirilis pertama kali tahun 2011. Framework PHP yang baru ini sedang mengalami perkembangan yang sangat pesat melalui komunitas yang dimilikinya. Framework ini menggunakan composer untuk menginstall dependensi yang ada didalamnya. Composer adalah sebuah 'dependency manager' untuk PHP. Anda bisa menginstall suatu library melalui composer dan composer akan secara otomatis menginstall library lain yang dibutuhkan, tanpa perlu mendownload satu persatu. Mirip dengan apt get install di sistem operasi linux. Dan seluruh library yang Anda butuhkan akan otomatis di download dan siap digunakan (Awaludin, 2015).

\section{METODE PENGEMBANGAN SISTEM \\ 3.1 Prototype}

Metode pembangunan perangkat lunak yang digunakan adalah model yang biasa disebut dengan Prototype. Model prototyping merupakan suatu teknik untuk mengumpulkan informasi tertentu mengenai kebutuhankebutuhan informasi pengguna secara cepat. Berfokus pada penyajian dari aspek-aspek perangkat lunak tersebut yang akan nampak bagi pelanggan atau pemakai. Prototipe tersebut akan dievaluasi oleh pelanggan/pemakai dan dipakai untuk menyaring kebutuhan pengembangan perangkat lunak (Susanto Rani ,2016). Dalam pengimplementasian metode Prototype pada sistem informasi audit energi listrik ini, peneliti mengimplementasikan metode SDLC (System Development Life Cycle). Prototype yang meliputi tahap Planning, Modeling, Construction, Deployment, dan Communication dapat dilihat pada gambar 1 berikut ini:

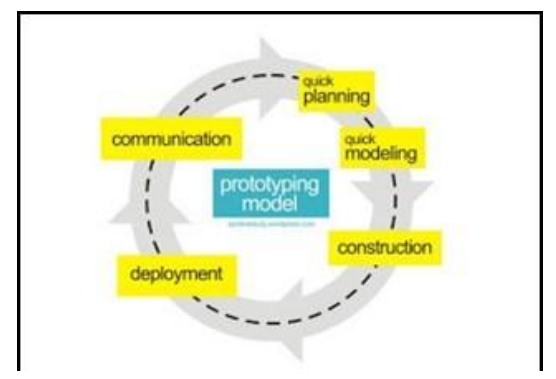

Gambar 1. Prototype Model

\section{PERANCANGAN}

Dalam pembuatan rancangan sistem informasi audit energi listrik berbasis laravel ini penulis menggunakan metode UML dan terdapat tiga diagram UML yang akan digunakan sesuai dengan kebutuhan sistem, yaitu:

\subsection{Use Case Diagram}

Pada gambar 2 merupakan diagram use case yang akan mempermudah dalam memahami peran dari setiap aktor dalam menggunakan system.

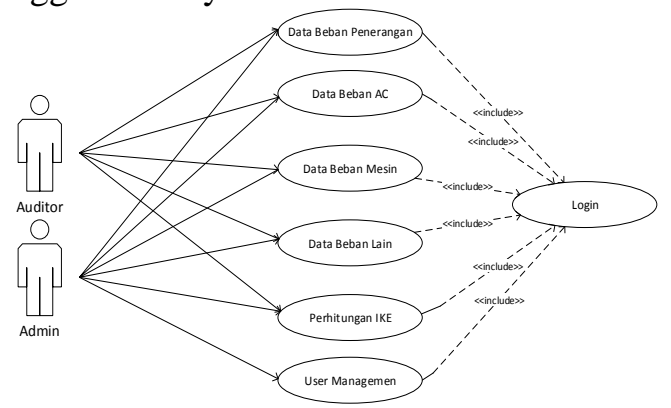

Gambar 2. Use Case Diagram

\subsection{Class Diagram}

Pada Gambar 3 menunjukkan class diagram yang digunakan sistem. Diagram ini digunakan untuk menampilkan kelas - kelas atau paket - paket di dalam sistem. 


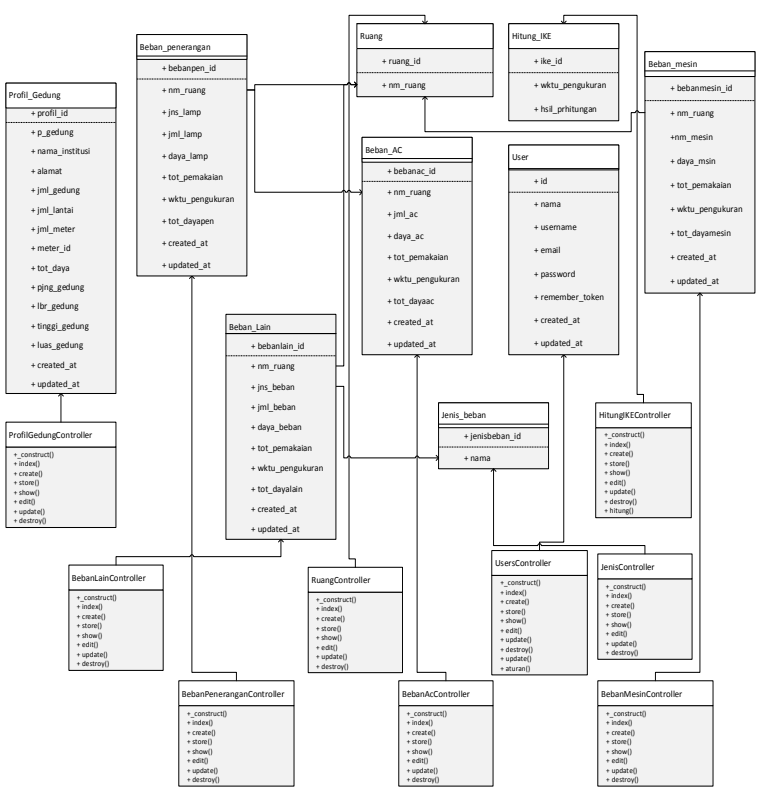

Gambar 3. Class Diagram

\subsection{Relasi Tabel}

Pada Gambar 4 merupakan diagram relasi tabel. Diagram ini digunakan untuk menampilkan data yang digunakan dalam sistem.

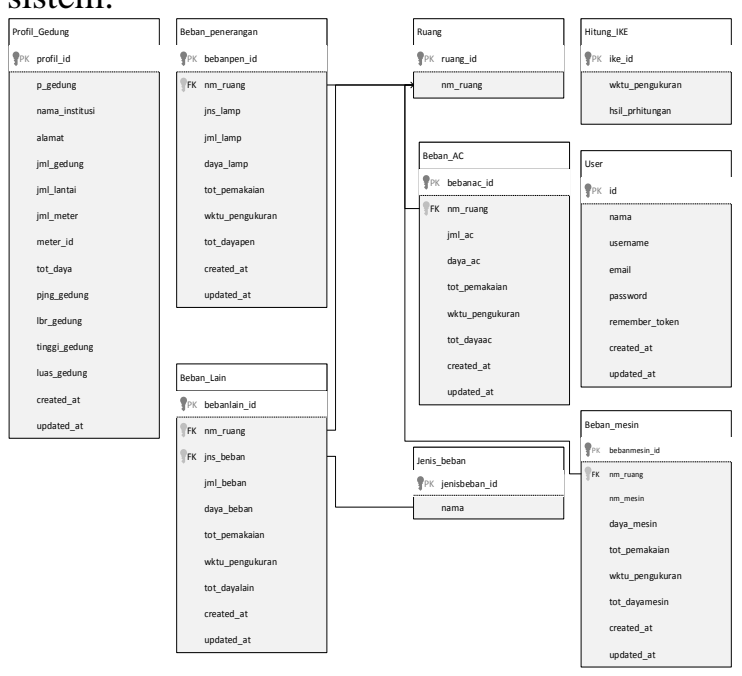

Gambar 4. ER Diagram

\section{HASIL DAN PEMBAHASAN}

Berikut beberapa tampilan dari Sistem Audit Energi Listrik dari beberapa hak akses yaitu : Guest, Admin, dan Auditor.

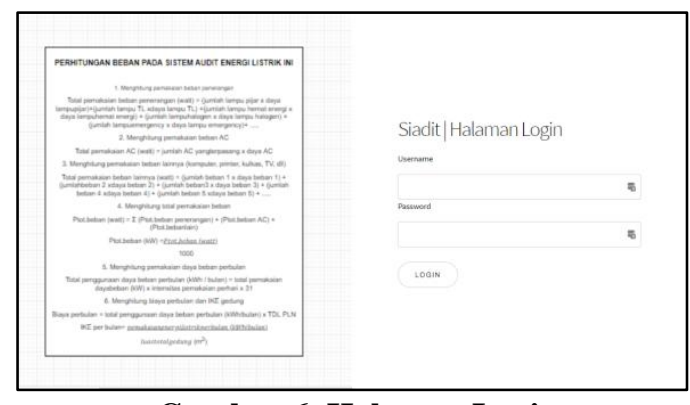

Gambar 6. Halaman Login

Gambar 6. merupakan halaman ketika guest membuka atau mengakses sistem.

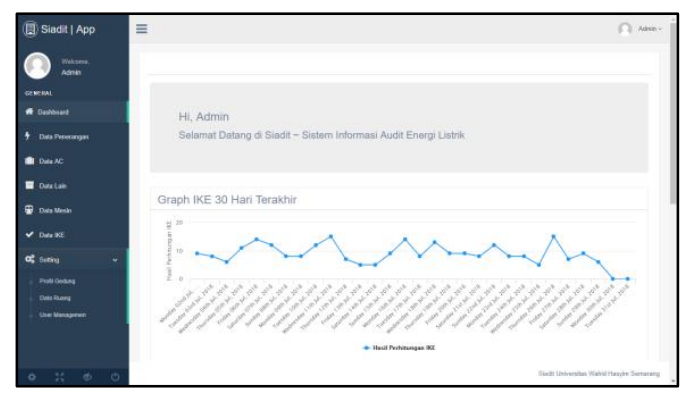

Gambar 7. Dashboard Admin

Gambar 7. merupakan halaman dashboard admin setelah login kedalam sistem.



Gambar 8. Dashboard Auditor

Gambar 8. merupakan halaman dashboard auditor setelah login kedalam sistem.

Berikut beberapa tampilan dari Sistem Audit Energi Listrik untuk perhitungan beban listrik yang ditunjukkan gambar 9, 10, 11 dan 12.

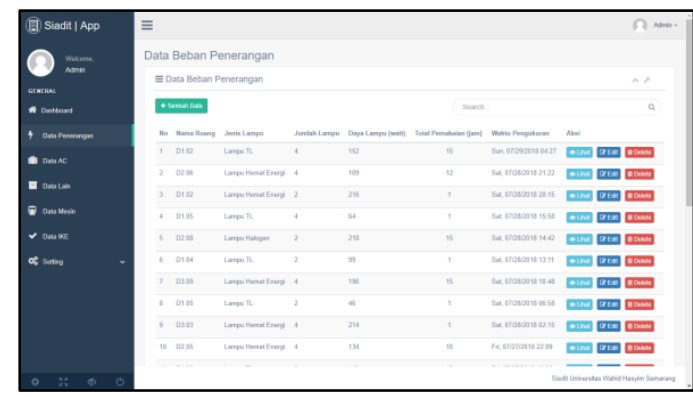

Gambar 9. Beban Daya Penerangan 


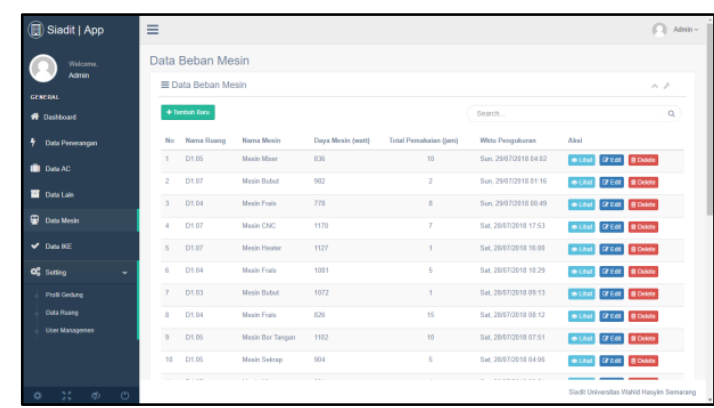

Gambar 10. Beban Daya Mesin

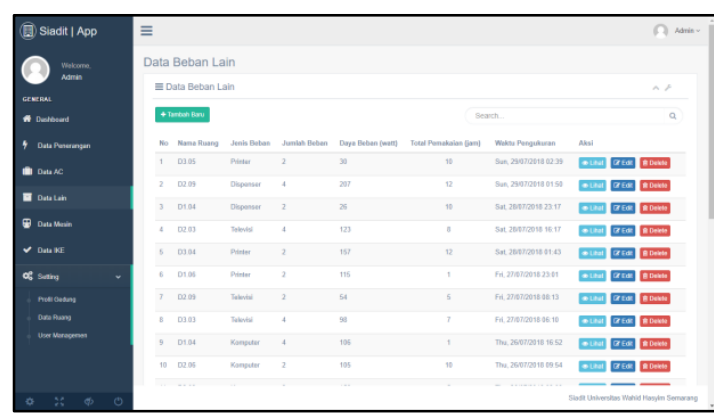

Gambar 11. Beban Daya Lain

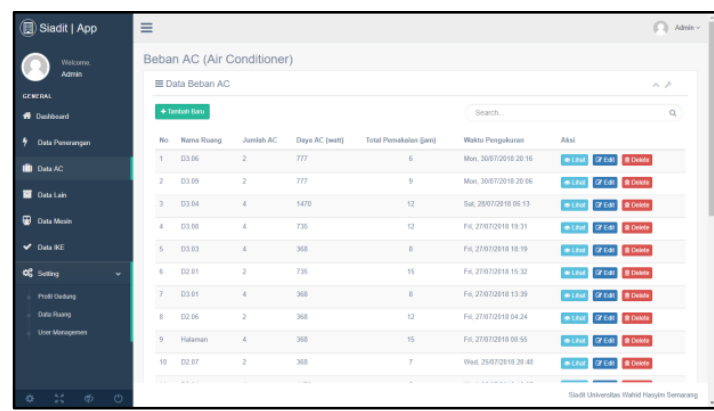

Gambar 12. Beban Daya AC

\section{KESIMPULAN}

Berdasarkan hasil pembahasan sebelumnya, maka dapat ditarik kesimpulan sebagai berikut:

a) Sistem informasi audit energi listrik ini memudahkan pengolahan data audit.

b) Sistem informasi audit energi listrik digunakan sebagai sarana analisis energi dan pengambilan kebijakan apakah akan dilakukan proses penghematan energi listrik atau tidak.

c) Dasboard sistem informasi audit energi listrik bersifat informatif yang berisi data grafik dan informasi hasil perhitungan IKE gedung.

d) Hasil data audit energi listrik singkat di Gedung D Universitas Wahid Hasyim adalah dinyatakan "Cukup Efisien" dengan nilai IKE rata-rata 13.11 .

\section{DAFTAR PUSTAKA}

Awaludin, Rahmat. 2015. Menyelami Framework Laravel. Jakarta: Lean Publishing

ESDM. 2015. Audit Energi ISO 50001. Jakarta: Kementrian ESDM.

SNI 03-6196-2011. Prosedur Audit Energi pada Bangunan Gedung. Jakarta: Biro Umum Sekretariat Jenderal Departemen Pendidikan Nasional, Oktober 2011. 